\title{
The synergistic effect of dual use of amphetamine-type stimulants and ketamine on drug-induced psychotic symptoms in Chinese synthetic drug users
}

\author{
Xue-Bing Liư ${ }^{1,2}$, Yao Zhang ${ }^{3}$, Xu-Yi Wang ${ }^{1}$ and Wei Hao ${ }^{1}$ \\ ${ }^{1}$ Mental Health Institute of the Second Xiangya Hospital, Central South University, The China National Clinical Research \\ Center for Mental Health Disorders, National Technology Institute of Psychiatry, Key Laboratory of Psychiatry and Mental \\ Health of Hunan Province, Changsha, Hunan, China \\ ${ }^{2}$ Affiliated Wuhan Mental Health Center, The Ninth Clinical School, Tongji Medical College of Huazhong University of Science \\ \& Technology, Wuhan, Hubei, China \\ ${ }^{3}$ Wuhan Wudong Hospital, Wuhan Second Mental Hospital, Wuhan, Hubei, China \\ Correspondence to: Yao Zhang, email: zhangyaowh@126.com
}

Wei Hao, email: weihao57@gmail.com

Keywords: amphetamine-type stimulants; ketamine; psychotic symptoms; synergistic effect

Received: January 31, $2017 \quad$ Accepted: March 11, $2017 \quad$ Published: March 22, 2017

Copyright: Liu et al. This is an open-access article distributed under the terms of the Creative Commons Attribution License 3.0 (CC BY 3.0), which permits unrestricted use, distribution, and reproduction in any medium, provided the original author and source are credited.

\section{ABSTRACT}

The use of amphetamine-type stimulants (ATS) and ketamine is of particular clinical concern because of its associated psychotic symptoms. In Chinese clinical practice, ATS and ketamine are commonly used simultaneously, but very few studies have reported the symptom profile of users who use both drugs. This study determined whether the combined use of ATS and ketamine is associated with more psychotic symptoms than either ATS or ketamine alone. According to drug use characteristics, 375 Chinese synthetic drug users were categorized into 2 pairs of comparison groups: ATS-only $(n=125)$ vs. ATS-mainly (ATS most of the time and ketamine sometimes, $n=150)$ and ketamine-only $(n=38)$ vs. ketamine-mainly (ketamine most of the time and ATS sometimes, $n=62$ ). We used the Chinese Brief Psychiatric Rating Scale (BPRS) to assess these patients' psychotic symptoms. ATS-mainly group had more anxiety/ depression and anergia symptoms than ATS-only group $(p<0.001)$, and ketaminemainly group had more thinking-disorder, activity and hostility-suspicion symptoms than ketamine-only group $(p \leq 0.001)$. These findings indicate that ATS may exacerbate the thinking-disorders, activity and hostility-suspicion symptoms of ketamine users, and ketamine may exacerbate anxiety/depression and anergia symptoms of ATS users.

\section{INTRODUCTION}

Over the past 2 decades, amphetamine-type stimulants (ATS) and ketamine have become increasingly prevalent in China [1-3]. According to China's Annual Report on Drug Control issued by the Narcotic Control Commission, the number of illicit drug users, who had been registered in the Department of Public Security, was 24.75 million in 2013; among them, synthetic drug users accounted for almost a half [4]. ATS and/ or ketamine dependence and/or abuse is of particularly clinical concern, because of its associated psychotic symptoms [5-8]. Recent studies reported that, $26-46 \%$ of individuals who use ATS or ketamine experienced psychotic symptoms [9], which occurred more frequently than cocaine [10] and cannabis users [11].

Previous research indicates that chronic/heavy ATS or ketamine use may induce psychotic symptoms resembling positive symptoms of schizophrenia, such as suspiciousness, delusions of persecution and hallucinations $[12,13]$, perceptual changes, ideas of reference, thought disorder [14-16], and some negative symptoms like blunted affect and diminished spontaneity [17, 18]. In China, one recent study reported more psychiatric symptoms and more severe drug-induced schizophrenialike symptoms in chronic methamphetamine users than 
chronic ketamine users [19]. However, findings from this study may have limited generality, because ATS and ketamine are often used together in China, which may lead to additional or more severe psychotic symptoms [20]. For example, one study conducted in the United States reported that ATS and ketamine taken together resulted in additive effects, leading to thought disorder, arousal, euphoria and less-than-additive effects on psychosis [21]. To the best of our knowledge, few clinical studies had investigated the synergistic effect of dual use of ATS and ketamine on drug-induced psychotic symptoms in China. Given the increasing number of users of ATS and ketamine in China, it is important to understand the effects of combination use on psychotic symptoms of synthetic drug users.

The current study examined psychotic symptoms among adult inpatients who diagnosed with ATS and/or Ketamine induced psychosis. To determine the synthetic effects of combined ATS and ketamine use on users' psychiatric symptom profiles, we compared psychotic symptoms between patients who use both ATS and ketamine, and ATS or ketamine alone.

\section{RESULTS}

\section{Basic characteristics of study participants}

The majority of participants in our sample were young males with low education levels and unstable jobs. Detailed demographic and drug use characteristics for the 4 groups were shown in Table 1 and Table 2. There were no statistically significant differences on demographic and drug use characteristics between the ATS-mainly group and the ATS-only group, and the ketamine-mainly group and the ketamine-only group.

\section{The association between combined use of ATS and ketamine and psychotic symptoms}

As displayed in Table 3, ATS-mainly group had more anxiety/depression and anergia symptoms than ATSonly group $(p<0.001)$, and ketamine-mainly group had more thinking-disorder, activity and hostility-suspicion symptoms than ketamine-only group $(P \leq 0.001)$. Overall, while there was no significant difference in BPRS total score between ATS-mainly and ATS-only groups $(P=$ $0.217)$, ketamine-mainly group scored significantly higher on BPRS than ketamine-only group $(P \leq 0.001)$.

\section{DISCUSSION}

In this study, we found that the anxiety/depression and anergia symptom scores of ATS-mainly group were significantly higher than ATS-only group, while the total
BPRS score, thought disorder, activity score and hostilitysuspicion symptoms of ketamine-mainly group were more prevalent than ketamine-only group. These results suggest that the psychotic symptoms induced by the combined use of ATS and ketamine are more severe than those induced by ATS/ ketamine alone. Our data indicate that ketamine use may exacerbate depression and anergia symptoms of ATS users and, ATS may exacerbate the thinkingdisorders, activity and hostility-suspicion symptoms of ketamine users.

Consistent with 2 earlier studies [21, 22], our findings suggest that the psychotic symptoms caused by the combination of ATS and ketamine are not the supra-additive or even fully additive psychotic effects of either ATS or ketamine alone. Previous studies have reported that the noncompetitive glutamate N-methylD-aspartate (NMDA) antagonist could regulate the dopamine release in nucleus accumbens [23-25]. Based on the dopamine hypothesis on mechanisms of psychotic symptoms of schizophrenia $[26,27]$, it seems that ATS and ketamine may share similar psychopathological mechanism, which results in a ceiling effect on psychotic symptoms. However, findings from our study were a little different from this hypothesis, that is, we found that ATS-mainly group had significantly more symptoms of depression and anergia than the ATS-only, whereas ketamine-mainly group had significant more symptoms of thought disorders and activity and hostility-suspicion. We, therefore, speculated that ATS and ketamine might still have different psychopathological mechanisms. These results were confirmed by our previous study, in which we found the ATS and ketamine user present with different profile of psychiatric symptoms [20]. It is possible that the interaction of ATS and ketamine, at the neurological level, affecting NMDA glutamate receptor and monoaminergic systems in the human brain, may antagonize some effects of the other drugs [28, 29], or the dopaminergic response induced by ketamine treatment, in general, acts as a compensatory mechanism [30-33], which exaggerates or attenuates the emergence of psychotic symptoms. Further experimental research is needed to understand the potential mechanism of combined ATS and ketamine on neural system.

There are some methodological limitations in this study. Firstly, this was an observational study, and we were not able to control all possible confounding factors such as the dosage of drugs that influence psychotic symptoms. Secondly, our study participants were inpatients from a large psychiatric specialty hospital. Some of them were admitted involuntarily and therefore these drug users may tend to be more aggressive and offensive. Hence, findings from this study may not be generalizable to other clinical settings. Thirdly, another commonly used scale of psychotic symptoms, the Positive and Negative Syndrome Scale (PANSS), which is more comprehensive in assessing psychotic symptoms than BPRS [34], was not used in this 
Table 1: Demographic characteristics of study participants

\begin{tabular}{|c|c|c|c|c|c|c|}
\hline Variables & $\underset{(n=150)}{\text { AST mainly }}$ & $\begin{array}{c}\text { ATS only } \\
(n=125)\end{array}$ & $P$ & $\underset{(n=62)}{K \text { mainly }}$ & $\begin{array}{l}\text { K only } \\
(n=38)\end{array}$ & $P$ \\
\hline \multicolumn{7}{|l|}{ Gender } \\
\hline Male & $125(83.3)$ & $99(79.2)$ & 0.380 & $49(79.0)$ & $30(78.9)$ & 0.591 \\
\hline Female & $25(16.7)$ & $26(20.8)$ & & $13(21.0)$ & $8(21.1)$ & \\
\hline \multicolumn{7}{|l|}{ Age } \\
\hline$\leq 20$ & $5(3.3)$ & $2(1.6)$ & 0.219 & $3(4.8)$ & $3(7.9)$ & 0.487 \\
\hline $21-30$ & $76(50.7)$ & $68(54.4)$ & & $33(53.2)$ & $19(50.0)$ & \\
\hline $1-40$ & $51(34.0)$ & $48(38.4)$ & & $20(32.3)$ & $15(39.5)$ & \\
\hline$>41$ & $18(12.0)$ & $7(5.6)$ & & $6(9.7)$ & $1(2.6)$ & \\
\hline \multicolumn{7}{|l|}{ Marital Status } \\
\hline Single & $68(45.3)$ & $48(38.4)$ & 0.474 & $28(45.2)$ & $21(55.3)$ & 0.107 \\
\hline Married & $64(42.7)$ & $62(49.6)$ & & $24(38.7)$ & $16(42.1)$ & \\
\hline Divorced/Separated & $18(12.0)$ & $15(12.0)$ & & $10(16.1)$ & $1(2.6)$ & \\
\hline \multicolumn{7}{|l|}{ Education levels } \\
\hline Less 9 years & $126(84.0)$ & $94(75.2)$ & 0.138 & $52(83.9)$ & $28(73.7)$ & 0.206 \\
\hline High school & $20(13.3)$ & $23(18.4)$ & & $5(8.1)$ & 7 (18.4) & \\
\hline College or above & $4(2.7)$ & $8(6.4)$ & & $5(8.1)$ & $3(7.9)$ & \\
\hline \multicolumn{7}{|l|}{ Occupation } \\
\hline Unemployed & $52(34.7)$ & $17(13.6)$ & $<0.001$ & $19(30.6)$ & $6(15.8)$ & 0.409 \\
\hline Businessman & $37(24.7)$ & $41(32.8)$ & & $12(19.4)$ & $10(26.3)$ & \\
\hline Entertainment & $11(7.3)$ & $6(4.8)$ & & $6(9.7)$ & $4(10.5)$ & \\
\hline Migrant worker & $50(33.3)$ & $61(48.8)$ & & $25(40.3)$ & $18(47.4)$ & \\
\hline \multicolumn{7}{|l|}{ Urine test } \\
\hline $\operatorname{ATS}(+)$ & 114 & 86 & --- & 3 & 0 & -- \\
\hline ATS (-) & 36 & 39 & & 59 & 0 & \\
\hline $\mathrm{K}(+)$ & 40 & 0 & & 58 & 17 & \\
\hline $\mathrm{K}(-)$ & 110 & 0 & & 4 & 21 & \\
\hline
\end{tabular}

Note: Values are given as number $(\%)$.

study. We would have more findings on the symptom profile of drug users if we used PANSS in the current study. Fourth, psychiatrists who assessed the psychotic symptoms were not blinded to drug use status of subjects. Finally, our study did not collect data on the duration of psychotic symptoms, because these symptoms can be chronic, acute, or both. This is a potential confounding factor that may bias the synergistic effect of dual use of ATS and ketamine, as demonstrated in this study.

In summary, this study provides some evidence of psychotic symptomatology for the synergistic effect of dual use of ATS and ketamine. It might be due to the interactions of NMDA glutamate receptor and monoaminergic systems in the human brain. One of the potential clinical implications is that ATS and ketamine may have different effects on psychopathology. Further mechanism research is needed to clarify the interaction between amphetamine and ketamine.

\section{MATERIALS AND METHODS}

\section{Participants}

Between January 2012 and December 2013, a total of 375 synthetic drug users admitted to the Drug Abuse Treatment Inpatient Ward of Wuhan Mental Health Center, were consecutively included in this study. The inclusion criteria were (1) met the criteria for "mental disorders due to psychoactive substance use/abuse" based on ICD$10[35,36]$, and (2) substances used were ATS and/or 
Table 2: Drug use characteristics of study participants

\begin{tabular}{|c|c|c|c|c|c|c|}
\hline Variables & $\begin{array}{c}\text { ATS mainly } \\
(n=150)\end{array}$ & $\begin{array}{c}\text { ATS only } \\
(n=150)\end{array}$ & $\boldsymbol{P}$ & $\underset{(n=62)}{K \text { mainly }}$ & $\begin{array}{l}\text { K only } \\
(n=38)\end{array}$ & $\boldsymbol{P}$ \\
\hline \multicolumn{7}{|l|}{ ATS } \\
\hline Age of first use & $20.32 \pm 6.12$ & $17.28 \pm 5.44$ & 0.185 & $21.15 \pm 7.69$ & & \\
\hline Range, yrs & $15-42$ & $13-36$ & & $17-40$ & & \\
\hline Duration, months & $44.20 \pm 13.27$ & $42.32 \pm 11.88$ & 0.327 & $18.41 \pm 4.72$ & & \\
\hline Range, months & $12-96$ & $6-102$ & & $9-36$ & & \\
\hline Frequency, per month & $16.11 \pm 6.44$ & $17.12 \pm 4.10$ & 0.43 & $3.78 \pm 2.98$ & & \\
\hline Range, per month & $10-28$ & $8-30$ & & $1-6$ & & \\
\hline Single dose, $\mathrm{g}$ & $0.45 \pm 0.43$ & $0.47 \pm 0.32$ & 0.114 & $0.28 \pm 0.34$ & & \\
\hline Range, $g$ & $0.1-0.2$ & $0.1-1.0$ & & $0.05-0.3$ & & \\
\hline \multicolumn{7}{|l|}{ Ketamine } \\
\hline Age of first use & $18.13 \pm 8.66$ & & & $20.13 \pm 8.19$ & $21.67 \pm 10.13$ & 0.560 \\
\hline Range,yrs & $12-36$ & & & $16-45$ & $18-51$ & \\
\hline Duration,months & $52.35 \pm 15.40$ & & & $62.92 \pm 18.86$ & $65.06 \pm 17.38$ & 0.384 \\
\hline Range,months & $30-108$ & & & $42-120$ & $38-114$ & \\
\hline Frequency,per month & $3.21 \pm 2.14$ & & & $10.19 \pm 4.87$ & $10.42 \pm 4.13$ & 0.782 \\
\hline Range,per month & $1-6$ & & & 4-14 & $2-16$ & \\
\hline Single dose,g & $0.35 \pm 0.32$ & & & $0.42 \pm 0.34$ & $0.45 \pm 0.42$ & 0.445 \\
\hline Range,g & $0.1-0.3$ & & & $0.2-0.6$ & $0.1-0.8$ & \\
\hline
\end{tabular}

Note: Values given as mean and standard deviations.

Table 3: Comparisons of BPRS scores between subjects of different drug use characteristics

\begin{tabular}{|l|c|c|c|c|c|c|c|c|}
\hline \multicolumn{1}{|c|}{ BPRS } & ATS mainly & ATS only & $\mathbf{t}$ & $\boldsymbol{P}$ & K mainly & K only & t & $\boldsymbol{P}$ \\
\hline Anxiety/depression & $1.93 \pm 0.84$ & $1.53 \pm 0.35$ & 4.975 & $<0.001$ & $3.18 \pm 0.76$ & $2.91 \pm 0.49$ & 1.953 & 0.053 \\
\hline Anergia & $1.30 \pm 0.30$ & $1.06 \pm 0.11$ & 8.48 & $<0.001$ & $1.85 \pm 0.55$ & $1.91 \pm 0.61$ & 0.508 & 0.613 \\
\hline Thinking-disorder & $3.00 \pm 0.80$ & $3.15 \pm 0.71$ & 1.629 & 0.105 & $2.16 \pm 0.62$ & $1.74 \pm 0.57$ & 3.389 & 0.001 \\
\hline Activity & $2.97 \pm 0.66$ & $3.06 \pm 0.68$ & 1.111 & 0.267 & $2.40 \pm 0.82$ & $1.61 \pm 0.32$ & 5.671 & $<0.001$ \\
\hline Hostility-suspicion & $4.62 \pm 0.82$ & $4.81 \pm 0.95$ & 1.78 & 0.076 & $3.51 \pm 1.05$ & $3.02 \pm 0.79$ & 2.477 & 0.015 \\
\hline Total score & $47.60 \pm 8.14$ & $46.50 \pm 6.24$ & 1.238 & 0.217 & $46.52 \pm 5.9$ & $40.13 \pm 7.68$ & 4.679 & $<0.001$ \\
\hline
\end{tabular}

ketamine. The exclusion criteria were (1) co-occurring use of heroin, cocaine, marijuana, and other illegal substances (excluding nicotine), (2) alcohol use disorders, and (3) major medical conditions. Two licensed senior psychiatrists conducted all diagnostic assessment and clinical interviews.

According to patients' self-reported drug use patterns, we divided all patients into 2 pairs of comparison groups: ATS-only group (used ATS only) $(n=125)$ vs. ATS-mainly group (used ATS most of the time and ketamine sometimes, $n=150$ ), and ketamine-only group (used ketamine only, $n=38$ ) vs. ketamine-mainly group (used ATS most of the time and ketamine sometimes) $(n=62)$. This study protocol was approved by the Ethics Committee of Wuhan Mental Health Center. All participants gave written informed consent.

\section{Demographics and drug use history}

As a routine clinical procedure, all patients were asked to provide demographic data (gender, age, education 
and occupation) and urine samples for urine toxicology tests. Enzyme multiplied immunoassay technique was used in urine tests to determine the types of drugs used, including ATS, ketamine, heroin, methadone, cocaine, cannabis, and benzodiazepines. Drug use history was reported by patients, and additionally verified by urine drug test results and their family members.

\section{Psychiatric symptom assessment}

On the day of admission, the Chinese Brief Psychiatric Rating Scale (BPRS) [37, 38] was administered to assess the psychotic and behavioral symptoms of drug users. The BPRS contains 18 items scored on a seven-point scale $(1=$ not present to $7=$ extremely severe). The Chinese BPRS is divided into 5 subscales: anxiety/depression, anergia, thinking-disorder, activity, and hostility-suspicion. In general, BPRS total score reflects the severity of psychopathology, while its subscale scores reflect the symptoms profiles of psychotic symptoms [39-41]. A high score is interpreted as having severe psychotic symptoms. The Chinese BPRS has been proved to reliable and valid to assess psychotic symptoms $[40,42]$.

\section{Statistical analyses}

All statistical procedures were carried out by using SPSS 20.0 for Windows. Independent sample $t$-test was used to compare the symptom scores between patients used dual drugs and a single drug. Chi-square test was used to compare the group differences for category variables. The statistical significance level was set at $p<$ 0.05 (two-sided).

\section{ACKNOWLEDGMENTS}

The authors thank all the research staff for their team collaboration work and all the patients who took part in this study.

\section{CONFLICTS OF INTEREST}

The authors declare no conflict of interest.

\section{GRANT SUPPORT}

This study was funded by the National Natural Science Foundation of China (Grant No.81571307, X. Wang, PI) the Key Program of the National Natural Science of China (81130020, W. Hao, PI) and National 973 Program (2015CB553500, W. Hao, PI).

\section{Editorial note}

This paper has been accepted based in part on peerreview conducted by another journal and the authors' response and revisions as well as expedited peer-review in Oncotarget.

\section{REFERENCES}

1. Bao YP, Liu ZM. Currents situation and trends of drug abuse and HIV/AIDS in China. HIV Therapy. 2009;3:237240.

2. Qian HZ, Schumacher JE, Chen HT, Ruan YH. Injection drug use and HIV/AIDS in China: Review of current situation, prevention and policy implications. Harm Reduct Journal. 2006;3:4.

3. Zhang Y, Lu C, Zhang J, Hu L, Song H, Li J, Kang L. Gender differences in abusers of amphetamine-type stimulants and ketamine in southwestern China. Addictive Behaviors. 2013;38: 1424-1430.

4. China's Annual Report on Drug Control. http://www. nncc626. com/index/ndbg.htm. 2013.

5. Krysta JH, Karper LP, Seibyl JP, Freeman GK, Delaney R, Bremner JD, Heninger GR, Bowers MB Jr, Charney DS. Subanesthetic effects of the noncompetitive NMDA antagonist, ketamine, in humans. Psychotomimetic, perceptual, cognitive, and neuroendocrine responses. Arch Gen Psychiatry. 1994;51:199-214.

6. Lahti AC, Koffel B, LaPorte D, Tamminga CA. Subanesthetic doses of ketamine stimulate psychosis in schizophrenia. Neuropsychopharmacology. 1995;13:9-19.

7. Curran C, Byrappa N, McBride A. Stimulant psychosis: systematic review. Br J Psychiatry. 2004;185:196-204.

8. McKetin R, McLaren J, Lubman DI, Hides L. The prevalence of psychotic symptoms among methamphetamine users. Addiction. 2006;101:1473-1478.

9. Grant KM, LeVan TD, Wells SM, Li M, Stoltenberg SF, Gendelman HE, Carlo G, Bevins RA. MethamphetamineAssociated Psychosis. J Neuroimmune Pharmacol. 2012; 7:113-119.

10. Mahoney JJ, Kalechstein AD, De La Garza R, Newton TF. Presence and persistence of psychotic symptoms in cocaineversus methamphetamine-dependence participants. Am J Addict. 2008; 17:83-98.

11. Smith MJ, Thirthalli J, Abdallah AB, Murray RM, Cottler LB. Prevalence of psychotic symptoms in substance users: a comparison across substances. Comprehensive Psychiatry. 2009;50:245-250.

12. Angrist B, Sathananthan G, Wilk S, Gershon S. Amphetamine psychosis: behavioral and biochemical aspects. Journal of Psychiatric Research. 1974;11:13-23.

13. Bell DS. Comparison of amphetamine psychosis and schizophrenia. British Journal of Psychiatry.1965; 111:701707. 
14. Ghoneim MM, Hinrichs JV, Mewaldt SP, Petersen RC. Ketamine: behavioral effects of subanesthetic doses. Journal of Clinical Psychopharmacology. 1985;5:70-77.

15. Lahti AC, Weiler MA, Tamara Michaelidis BA, Parwani A, Tamminga CA. Effects of ketamine in normal and schizophrenic volunteers. Neuropsychopharmacology. 2001;25:455-467.

16. Mason OJ, Morgan CJ, Stefanovic A, Curran HV. The psychotomimetic states inventory (PSI): measuring psychotic-type experiences from ketamine and cannabis. Schizophrenia Research. 2008;103:138-142.

17. Srisurapanont M, Ali R, Marsden J, Sunga A, Wada K, Monteiro M. Psychotic symptoms in methamphetamine psychotic in-patients. Int $\mathrm{J}$ Neuropsychopharmacol. 2003;6:347-352.

18. Yui K, Ikemoto S, Ishiguro $\mathrm{T}$, Goto K. Studies of amphetamine or methamphetamine psychosis in Japan. Ann NY Acad Sci. 2000; 914:1-12.

19. Liao Y, Qi C, Wu Q, Tang J. Psychiatric symptoms in individuals who use ketamine versus methamphetamineimplications for glutamatergic and dopaminergic model for schizophrenia: a cohort study. Lancet. 388: 67.

20. Zhang Y, Xu Z, Zhang S, Desrosiers A, Schottenfeld RS, Chawarski MC. Profiles of psychiatric symptoms among amphetamine type stimulant and ketamine using in patients in Wuhan, China. J Psychiatr Res. 2014;53:99-102.

21. Krystal JH, Perry EB Jr, Gueorguieva R, Belger A, Madonick SH, Abi-Dargham A, Cooper TB, Macdougall L, Abi-Saab W, D'Souza DC. Comparative and interactive human psychopharmacologic effects of ketamine and amphetamine: Implications for glutamatergic and dopaminergic model psychoses and cognitive function. Archives of General Psychiatry. 2005;62:985-994.

22. Kegeles LS, Abi-Dargham A, Zea-Ponce Y, RodenhiserHill J, Mann JJ, Van Heertum RL, Cooper TB, Carlsson A, Laruelle M. Modulation of amphetamine-induced striatal dopamine release by ketamine in humans: implications for schizophrenia. Biol Psychiatry. 2000,48:627-640.

23. Marcus MM, Mathe JM, Nomikos GG, Svensson TH. Effects of competitive and non-competitive NMDA receptor antagonists on dopamine output in the shell and core subdivisions of the nucleus accumbens. Neuropharmacology. 2001;40:482-490.

24. Mathe JM, Nomikos GG, Schilstrom B, Svensson TH. Non-NMDA excitatory amino acid receptors in the ventral tegmental area mediate systemic dizocilpine (MK-801) induced hyperlocomotion and dopamine release in the nucleus accumbens. J Neurosci Res. 1998; 51: 583-592.

25. Zhong BL, Li SH, Lv SY, Tian SL, Liu ZD, Li XB, Zhuang HQ, Tao R, Zhang W, Zhuo CJ. Suicidal ideation among Chinese cancer inpatients of general hospitals: Prevalence and correlates. Oncotarget. 2017; 8:25141-25150. doi: 10.18632/oncotarget.15350.

26. Meltzer HY, Stahl SM. The dopamine hypothesis of schizophrenia: a review. Schizophrenia Bulletin. 1976;
2:19-76.

27. Shu Q, Duan ZG, Hu G. Psychological mechanisms of dopamine in psychotic symptoms of schizophrenia: Recent theoretical and empirical advances. [in Chinese]. Chin Sci Bull (Chin Ver). 2012; 57:3384-3398.

28. Greenberg BD, Segal DS. Acute and chronic behavioral interactions between phencyclidine (PCP) and amphetamine: evidence for a dopaminergic role in some PCP-induced behaviors. Pharmacol Biochem Behav. 1985;23:99-105.

29. Moghaddam B, Bolinao ML. Glutamatergic antagonists attenuate ability of dopamine uptake blockers to increase extracellular levels of dopamine: implications for tonic influence of glutamate on dopamine release. Synapse. 1994;18:337-342.

30. Aalto S, Ihalainen J, Hirvonen J, Kajander J, Scheinin H, Tanila H, Nagren K, Vilkman H, Gustafsson LL, Syvalahti E, Hietala J. Cortical glutamate-dopamine interaction and ketamine-induced psychotic symptoms in man. Psychopharmacology. 2005;182:375-383.

31. Zhong BL, Chen SL, Conwell Y. Effects of Transient Versus Chronic Loneliness on Cognitive Function in Older Adults: Findings From the Chinese Longitudinal Healthy Longevity Survey. Am J Geriatr Psychiatry. 2016;24:389398.

32. Zhong BL, Chen SL, Tu X, Conwell Y. Loneliness and Cognitive Function in Older Adults: Findings From the Chinese Longitudinal Healthy Longevity Survey. J Gerontol B Psychol Sci Soc Sci. 2017;72:120-128.

33. Zhong BL, Liu TB, Chan SS, Jin D, Hu CY, Dai J, Chiu HF. Common mental health problems in rural-to-urban migrant workers in Shenzhen, China: prevalence and risk factors. Epidemiol Psychiatr Sci. 2017 Jan 9. [Epub ahead of print].

34. Daving Y, Andren E, Nordholm L, Grimby G. Reliability of an interview approach to the Functional Independence Measure. Clin Rehabil. 2001;15:301.

35. World Health Organization. The ICD-10 Classification of Mental and Behavioral Disorders. Diagnostic Criteria for Research. Geneva. 1993.

36. Zhong BL, Chiu HF, Conwell Y. Rates and characteristics of elderly suicide in China, 2013-14. J Affect Disord. 2016;206:273-279.

37. Hedlund JL, Vieweg BW. The Brief Psychiatric Rating Scale (BPRS): A comprehensive review. Journal of Operational Psychiatry. 1980;11:48-62.

38. Song $\mathrm{H}$, Li J, Lu Y, Deng L, Sun XL. Investigation of mental health and its influence on Chinese cancer patients using a multidisciplinary screening flow: an epidemiological survey in the west of China. Chin Med J (Eng1). 2013;126:61-67.

39. Burger GK, Calsyn RJ, Morse GA, Klinkenberg WD. Prototypical profiles of the brief psychiatric rating scale. Journal of Personality Y Assessment. 2000;75:373-386. 
40. Zhang MY, Wang ZY. Application of Chinese translation of the brief psychiatric rating scale. Chinese Journal of Neuropsychiatry Disease. 1984;10:157-160.

41. Zhong BL, Chiu HF, Conwell Y. Elderly suicide trends in the context of transforming China, 1987-2014. Sci Rep. 2016;6:37724.

42. Song J, Fei L, Zhang P, JI Z. Evaluation on each subscale of BPRS. J Clin Psychol Med. 2001; 11: 86-88. 